\title{
ENSINO HÍBRIDO E DESEMPENHO EM MATEMÁTICA NO ENSINO MÉDIO NA REDE PÚBLICA DO ESTADO DE SÃO PAULO
}

\section{HYBRID TEACHING AND MATHEMATICS PERFORMANCE IN HIGH SCHOOL IN THE PUBLIC SYSTEM OF THE STATE OF SÃO PAULO}

\section{EDUCACIÓN HÍBRIDA Y DESEMPEÑO EN MATEMÁTICAS EN LA ESCUELA SECUNDARIA EN LA RED PÚBLICA DEL ESTADO DE SÃO PAULO}

\begin{abstract}
Marco Antonio Campos ${ }^{1}$
e321093

https://doi.org/10.47820/recima21.v3i2.1093

\section{RESUMO}

A educação estadual pública paulista no ano letivo de 2021 marcou o início do ensino híbrido, em virtude da pandemia mundial de Covid-19, com os estudantes frequentando as aulas em momentos presenciais e em outros acompanhando as aulas no formato on-line. O desempenho dos estudantes na disciplina de Matemática nesta fase de ensino híbrido foi medido através de avaliações padronizadas e aplicadas pela Secretaria de Educação do Estado de São Paulo, Seduc-SP, em toda a rede. A divulgação do desempenho e participação nestas avaliações possibilitou a comparação dos resultados, para o Ensino Médio de uma escola pertencente a Diretoria de Ensino de Mogi Mirim, com toda a rede estadual. Identificando na inicial similaridade entre os resultados é possível a elaboração e o aperfeiçoamento de parâmetros para a melhoria e aumento de participação nas aulas ofertados no formato de ensino híbrido, para que o processo de aprendizagem dos estudantes seja próximo e até melhor que no ensino tradicional presencial.
\end{abstract}

PALAVRAS-CHAVE: Desempenho Escolar. Educação pública. Matemática. Ensino Híbrido. Ensino Médio

\begin{abstract}
São Paulo state public education in the school year of 2021 has marked the beginning of hybrid education, due to the Covid-19 worldwide pandemic, students attending classes in person and in other times attending the classes in the online way. The students performance in the Maths in this hybrid teaching phase was measured through standardized assessments applied by the Education Department of São Paulo State, Seduc-SP, throughout all schools. The performance disclosure and attendance in these evaluations made possible to compare the results, for the High School of a school belonging to the Education Directory of Mogi Mirim, with the entire state schools. Initially identifying similarity between the results, it is possible to design and refine parameters to improve and increase participation in classes offered in the hybrid teaching format, so that the students learning process is closer and even better than in traditional face-to-face teaching.
\end{abstract}

KEYWORDS: School Performance. Public Education. Mathematics. Hybrid Education. High School

\section{RESUMEN}

La educación pública de São Paulo en el año escolar 2021 marcó el inicio de la educación híbrida, debido a la pandemia mundial de Covid-19, con estudiantes que asisten a clases en momentos presenciales y en otros que acompañan las clases en formato en línea. El desempeño de los estudiantes en la disciplina de Matemáticas en esta fase de enseñanza híbrida fue medido a través de evaluaciones estandarizadas y aplicadas por el Departamento de Educación del Estado de São Paulo, Seduc-SP, en toda la red. La difusión del desempeño y la participación en estas evaluaciones permitió la comparación de los resultados, para la Escuela Secundaria de una escuela perteneciente a la Junta de Educación de Mogi Mirim, con toda la red estatal. Identificando en la similitud inicial entre los resultados es posible elaborar y mejorar parámetros para la mejora y aumento de la participación en las clases ofrecidas en

\footnotetext{
1 Secretaria da Educação do Estado de São Paulo - Seduc - SP

RECIMA21 - Ciências Exatas e da Terra, Sociais, da Saúde, Humanas e Engenharia/Tecnologia
} 


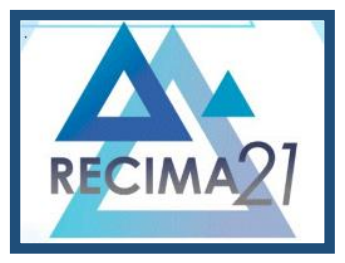

\section{RECIMA21 - REVISTA CIENTÍFICA MULTIDISCIPLINAR ISSN 2675-6218}

ENSINO HÍBRIDO E DESEMPENHO EM MATEMÁTICA NO ENSINO MÉDIO NA REDE PÚBLICA DO ESTADO DE SÃO PAULO Marco Antonio Campos

el formato de enseñanza híbrida, de manera que el proceso de aprendizaje de los estudiantes sea cercano e incluso mejor que en la enseñanza tradicional en el aula.

PALAVRAS-CHAVE: Desempeño Escolar. Educación Pública. Matemáticas. Educación Híbrida. Escuela Secundaria

\section{INTRODUÇÃO}

A pandemia mundial de Covid-19 trouxe novos hábitos ao cotidiano de toda a sociedade. $\mathrm{Na}$ área da educação alterações no formato das aulas foram implantados para continuidade da aplicação do conteúdo programático de cada ano e série, em todos os níveis de ensino, dos Anos Iniciais do Ensino Fundamental até os cursos superiores e de pós-graduação.

No primeiro semestre de 2021, a Secretaria de Educação do Estado de São Paulo, Seduc-SP, iniciou a metodologia do ensino híbrido, onde para o cumprimento das medidas de isolamento social as classes de aula da rede pública foram divididas em turmas.

Assim, por exemplo, determinada quantidade de estudantes frequentava um período uma semana de aula presencial e ficava duas semanas acompanhando aulas on-line transmitidas por um aplicativo específico da Seduc-SP, o Centro de Mídias SP, CMSP.

Com isso, o currículo foi aplicado em sua totalidade, não sendo a princípio os alunos prejudicados quando ao conteúdo, entretanto, há potencialidade de defasagem na aprendizagem, devido aos resultados analisados neste trabalho. Porém, o conceito ensino híbrido, na forma que foi apresentado, divulgado e aplicado, como aulas on-line e presencial é apenas uma parte do seu conceito amplo que envolve o uso de espaços, tempos, atividades, metodologias e público variados no processo de educar (MORAN, 2015).

O ano letivo de 2020, início da pandemia de Covid-19, teve alteração no formato das aulas para o cumprimento do conteúdo programático, conforme "Proposta de parecer sobre reorganização dos calendários escolares e realização de atividades pedagógicas não presenciais durante o período de pandemia da Covid-19", emitida pelo Conselho Nacional de Educação, CNE, vinculado ao Ministério da Educação, MEC.

Esta proposta, para o Ensino Fundamental Anos Finais e Ensino Médio contempla ações pedagógicas como:

- Elaboração de sequências didáticas construídas em consonância com as habilidades e competências preconizadas por cada área de conhecimento na BNCC;

- Verificar a possibilidade de se utilizar horários de TV aberta para levar programas educativos compatíveis para adolescentes e jovens;

- Distribuição de vídeos educativos (de curta duração) por meio de plataformas on-line, mas sem a necessidade de conexão simultânea seguidos de atividades a serem realizadas com a supervisão dos pais;

- Realização de atividades on-line síncronas de acordo com a disponibilidade tecnológica;

- Oferta de atividades on-line assíncronas de acordo com a disponibilidade tecnológica;

RECIMA21 - Ciências Exatas e da Terra, Sociais, da Saúde, Humanas e Engenharia/Tecnologia 


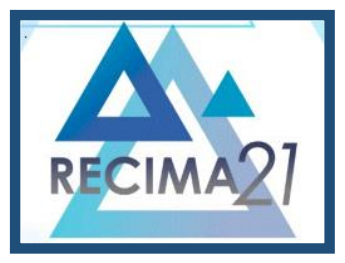

\section{RECIMA21 - REVISTA CIENTÍFICA MULTIDISCIPLINAR ISSN 2675-6218}

- Estudos dirigidos, pesquisas, projetos, entrevistas, experiências, simulações e outros;

- Realização de testes on-line ou por meio de material impresso a serem entregues ao final do período de suspensão das aulas, e;

- Utilização de mídias sociais de longo alcance (WhatsApp, Facebook, Instagram etc.) para estimular e orientar os estudos, desde que observadas as idades mínimas para o uso de cada uma dessas redes sociais (BRASIL, 2020).

Todas estas propostas foram aplicadas no ano letivo de 2020 e aperfeiçoadas em $2021 \mathrm{com}$ a implantação do ensino híbrido na rede estadual pública paulista.

Porém, problemas foram identificados em 2020 por professores e estudantes como dificuldade de interação professor/aluno e aluno/aluno, treinamento dos docentes para aperfeiçoamento das aulas e aplicação de novas metodologias de ensino. Destaca-se também a dificuldade de acesso à internet e aos equipamentos de informática.

Por estes fatores acima pode-se concluir, na inicial, que o ensino híbrido na rede estadual pública paulista não atingiu todos os seus objetos e também não alcançou todos os públicos de forma ampla e eficaz.

Com a publicação do trabalho de Campos (2021) que analisou a participação e o desempenho no componente curricular de Matemática para o Ensino Fundamental Anos Finais torna-se necessário a expansão da pesquisa para o Ensino Médio.

A partir desta premissa realizou-se a análise da participação e do desempenho em Matemática para o Ensino Médio na realização de três avaliações aplicadas pela Seduc-SP no $1^{\circ}$ semestre de 2021.

Os resultados foram obtidos nas avaliações: ADE (Avaliação Diagnostica de Entrada) de formato impresso, aplicada no período das aulas presenciais, e $1^{\circ}$ AAP e $2^{\circ}$ AAP (Avaliação de Aprendizagem e Processo), de formato digital, aplicadas durante as aulas no período de ensino híbrido, via Plataforma CAEd, parceria da Seduc-SP com o Centro de Políticas Públicas e Avaliação da Educação da Universidade Federal de Juiz de Fora (CAEd/UFJF).

A comparação dos dados foi entre a média de toda a rede pública com uma escola do município de Mogi Mirim, pertencente a Diretoria de Ensino de Mogi Mirim, DE Mogi Mirim, e indicam uma baixa taxa de participação e no desempenho nas avaliações ilustrando que o ensino híbrido aplicado no $1^{\circ}$ semestre de 2021 cumpriu com a aplicação do conteúdo, porém, o aprendizado ficou abaixo de $50 \%$ indicando que ações devem ser aperfeiçoadas e outras novas aplicadas para o êxito do sistema de ensino com aumento dos índices de participação e desempenho e maior aprendizagem.

\section{DESENVOLVIMENTO}

O sistema de ensino híbrido adotado no $1^{\circ}$ semestre do ano letivo de 2021 na rede pública do estado de São Paulo teve seu desempenho e participação mensurados a partir de avaliações aplicadas para toda a rede. Dois foram os tipos de avaliações:

- Avaliação Diagnóstica de Entrada - ADE: Possibilita o levantamento de informações sobre determinado contexto, permitindo a (re)organização e o (re)planejamento do processo de ensino e 


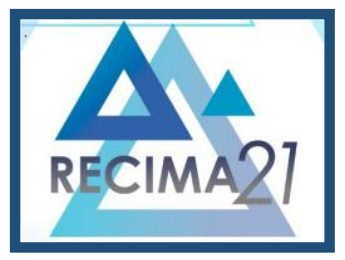

\section{RECIMA21 - REVISTA CIENTÍFICA MULTIDISCIPLINAR ISSN 2675-6218}

aprendizagem de acordo com o diagnóstico observado no início do ano letivo de 2021. Esta avaliação fornece um diagnóstico da situação educacional e escolar dos estudantes, unidades escolares e redes de ensino, identificando os conhecimentos, as aptidões e as habilidades, desenvolvidos até aquele momento pelos estudantes.

- Avaliação de Aprendizagem em Processo - AAP: classificada como Avaliação Formativa, a AAP ocorre durante o processo educacional, tendo como foco o currículo, pois, permite 0 acompanhamento do desenvolvimento dos estudantes, ao longo de determinado período, identificando se os objetivos de aprendizagem previstos pelo currículo, para aquele período, estão sendo ou foram alcançados. Seus resultados permitem ao professor ajustar sua prática docente às necessidades dos estudantes. Esse tipo de avaliação permite a geração de informações com rapidez, estabelecendo um diálogo contínuo entre o ensino e a aprendizagem (Adaptado Plataforma CAEd, 2021 (a)).

Tabela 1. Avaliações aplicadas no $1^{\circ}$ semestre do ano letivo de 2021.

\begin{tabular}{|l|l|l|}
\hline Avaliação & $\begin{array}{l}\text { Período de } \\
\text { Aplicação }\end{array}$ & Características \\
\hline ADE & $\begin{array}{l}\text { Início Ano } \\
\text { Letivo 2021 }\end{array}$ & $\begin{array}{l}\text { Estudantes frequentando as aulas no sistema presencial, e com a } \\
\text { prova no formato impressa, sendo o professor de cada sala } \\
\text { responsável por digitar no sistema o gabarito de cada prova. }\end{array}$ \\
\hline $\mathbf{1}^{\circ}$ AAP & $\begin{array}{l}\text { Final do } 1^{\circ} \\
\text { bimestre }\end{array}$ & $\begin{array}{l}\text { Aulas no formato híbrido, e as provas no formato digital realizadas na } \\
\text { Plataforma CAEd, onde cada estudante acessa seu caderno de prova } \\
\text { por meio de informações de usuário e senha pessoais. Ao iniciar uma } \\
\text { avaliação o prazo máximo para conclusão é de 48 horas, com isso o } \\
\text { aluno pode otimizar o tempo de realização junto com outras } \\
\text { atividades. }\end{array}$ \\
\hline $\mathbf{2}^{\circ}$ AAP & $\begin{array}{l}\text { Final do } 2^{\circ} \\
\text { bimestre }\end{array}$ \\
\hline
\end{tabular}

Fonte: Autoria própria.

Como destaque para a realização das avaliações na Plataforma CAEd os professores da classe/disciplina e a equipe gestora tem acesso diário ao status de realização da avaliação de cada estudante.

Esta plataforma também disponibiliza, ao final do período de aplicação, os resultados das avaliações, de todas as séries e turmas para a consulta de todos os professores da unidade escolar, além de identificar as habilidades cobradas nas avaliações e o percentual de acertos, facilitando a recuperação paralela.

A disponibilização das taxas médias de participação e acertos de toda a rede é mais um potencial indicativo para comparação dos resultados, indicando potenciais falhas e corrigindo-as por meio de trocas de experiências entre os docentes de uma escola e até em nível regional e estadual.

A participação dos estudantes, do Ensino Médio, nas avaliações ADE, $1^{\circ}$ AAP e $2^{\circ}$ AAP aplicadas no $1^{\circ}$ semestre do ano letivo de 2021 é objeto de comparação de uma escola estadual do município de Mogi Mirim, pertencente a Diretoria de Ensino de Mogi Mirim, DE Mogi Mirim, com a média de toda a rede estadual, conforme apresentado na Tabela 2.

A princípio observa-se uma similaridade na participação da escola analisada com a rede estadual. Outro ponto a destacar é o turno de oferecimento das turmas na escola analisada, sendo 


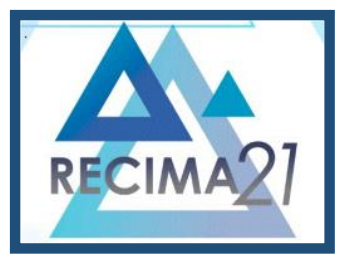

\section{RECIMA21 - REVISTA CIENTÍFICA MULTIDISCIPLINAR ISSN 2675-6218}

distribuídas no período matutino e noturno em todas as séries, considerando com isso a média de cada série.

Quando da aplicação da ADE as aulas ainda era oferecidas no sistema presencial, por este motivo a unidade escolar analisada apresentou participação considerável, com $63 \%$ de participação para a $1^{\circ}$ Série, $48 \%$ para a $2^{\circ}$ Série e para a $3^{\circ}$ Série a participação foi de $58 \%$. Todos estes valores foram superiores à média estadual que foi de $45 \%, 42 \%$ e $43 \%$, respectivamente.

Com a suspensão das aulas presenciais e oferecimento do ensino no sistema híbrido na rede estadual paulista, um fato já esperado, que era diminuição na participação dos alunos, foi observado na porcentagem de participação dos estudantes na aplicação das avaliações AAP.

Tabela 2. Percentual de participação nas avaliações padronizadas pela Seduc-SP no $1^{\circ}$ semestre do ano letivo de 2021.

\begin{tabular}{|l|c|c|c|c|c|c|}
\hline \multirow{2}{*}{$\begin{array}{l}\text { Ensino } \\
\text { Médio }\end{array}$} & \multicolumn{4}{|c|}{ Percentual de Participação - Matemática } \\
\cline { 2 - 7 } & \multicolumn{2}{|c|}{ ADE } & \multicolumn{2}{c|}{$\mathbf{1}^{\circ}$ AAP } & \multicolumn{2}{c|}{$\mathbf{2}^{\circ}$ AAP } \\
\cline { 2 - 7 } & Rede & Escola & Rede & Escola & Rede & Escola \\
\hline $\mathbf{1}^{\circ}$ Série & 45 & 63 & 35 & 31 & 39 & 35 \\
\hline $\mathbf{2}^{\circ}$ Série & 42 & 48 & 33 & 27 & 33 & 25 \\
\hline $\mathbf{3}^{\circ}$ Série & 43 & 58 & 33 & 43 & 34 & 27 \\
\hline
\end{tabular}

Fonte: Adaptado Plataforma CAEd, 2021 (b).

$\mathrm{Na} 1^{\circ}$ AAP aplicada no final do $1^{\circ}$ bimestre a participação da escola analisada ficou em $31 \%$ para a $1^{\circ}$ Série e em $27 \%$ para a $2^{\circ}$ Série, valores estes inferiores à média estadual que foi de $35 \% \mathrm{e}$ $33 \%$, respectivamente. Entretanto, para a $3^{\circ}$ Série a participação da unidade escolar foi de $43 \%$, superior a participação de $33 \%$ da rede.

Ao final do $2^{\circ}$ bimestre do ano letivo de 2021 foi aplicada a $2^{\circ}$ AAP e a participação da unidade escolar analisada foi inferior à média estadual, sendo de $35 \%$ para a $1^{\circ}$ Série da UE e de $39 \%$ para a rede. Na $2^{\circ}$ Série a participação foi de $25 \%$ para a UE e de $33 \%$ para a rede. A participação da unidade escolar analisada atingiu $27 \%$ para a $3^{\circ}$ Série ao passo que na rede este índice foi de $34 \%$.

Os baixos índices de participação para a realização das $1^{\circ} \mathrm{AAP}$ e $2^{\circ} \mathrm{AAP}$, avaliações estas aplicadas durante o sistema de ensino híbrido em toda a rede paulista, indicam a dificuldade dos alunos em acessar a internet, pois é estimado que $20 \%$ da população brasileira não tem acesso à internet (SOUTO, 2021) para o acompanhamento e realização das avaliações. Soma-se a estes fatores a instabilidade no sistema, Plataforma CAEd, conforme relato dos estudantes.

Mesmo com as ações da Seduc-SP em oferecer chip de celular, bem como as escolas agendarem, para os alunos sem acesso à internet, a realização das avaliações nas salas de informática, ao observar apenas a porcentagem de participação pode-se afirmar que o ensino híbrido na rede estadual paulista precisa ser mais igualitária ao ensino presencial, isto é, precisa ser disponibilizadas ferramentas que permitam uma maior participação dos estudantes nas aulas neste sistema de ensino.

Aliada a participação torna-se necessária a análise do desempenho dos estudantes na disciplina de Matemática. Na Tabela 3 tem-se os dados referentes ao desempenho, percentual de 


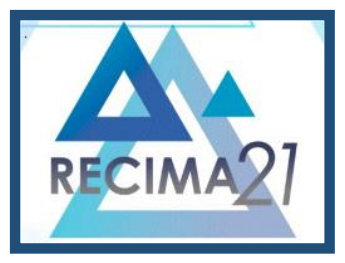

\section{RECIMA21 - REVISTA CIENTÍFICA MULTIDISCIPLINAR ISSN 2675-6218}

ENSINO HÍBRIDO E DESEMPENHO EM MATEMÁTICA NO ENSINO MÉDIO NA REDE PÚBLICA DO ESTADO DE SÃO PAULO Marco Antonio Campos

acerto, da unidade escolar analisada com a média da rede estadual nas avaliações ADE, $1^{\circ} \mathrm{AAP}$ e $2^{\circ}$ AAP para o Ensino Médio.

Observa-se na inicial que o percentual de acertos foi próximo a 50\%, indicando que ações devem ser implantadas para elevação deste índice.

A análise do desempenho na avaliação ADE, aplicada quando as aulas ainda estavam no sistema presencial e com conteúdo referente ao ano anterior, para ser um instrumento balizador da recuperação intensiva das primeiras semanas de aula, representam os maiores percentuais.

Tabela 3. Percentual de acertos nas avaliações padronizadas pela Seduc-SP no $1^{\circ}$ semestre do ano letivo de 2021.

\begin{tabular}{|l|c|c|c|c|c|c|}
\hline \multirow{2}{*}{$\begin{array}{l}\text { Ensino } \\
\text { Médio }\end{array}$} & \multicolumn{5}{|c|}{ Percentual de Desempenho - Matemática } \\
\cline { 2 - 7 } & \multicolumn{2}{|c|}{ ADE } & \multicolumn{2}{c|}{$\mathbf{1}^{\circ}$ AAP } & \multicolumn{2}{c|}{$\mathbf{2}^{\circ}$ AAP } \\
\cline { 2 - 7 } & Rede & Escola & Rede & Escola & Rede & Escola \\
\hline $\mathbf{1}^{\circ}$ Série & 59 & 66 & 54 & 44 & 46 & 46 \\
\hline $\mathbf{2}^{\circ}$ Série & 60 & 50 & 51 & 46 & 55 & 55 \\
\hline $\mathbf{3}^{\circ}$ Série & 55 & 53 & 54 & 49 & 49 & 46 \\
\hline
\end{tabular}

Fonte: Adaptado Plataforma CAEd, 2021 (b).

Para a $1^{\circ}$ Série o desempenho foi de $66 \%$ de acertos, frente a $59 \%$ na média da rede, na $2^{\circ}$ Série a unidade escolar apresentou desempenho de $50 \%$ sendo de $60 \%$ na rede estadual. Para a $3^{\circ}$ Série o percentual de acertos foi similar, de 53\% na escola analisada e de 55\% na rede.

Como toda a novidade do ensino híbrido, apesar de que parte do ano letivo de 2020 na rede estadual paulista teve aulas no formato virtual, o desempenho em Matemática tanto em nível local como estadual, nas avaliações AAP, apresentou valores inferiores aos obtidos na ADE.

Ao final do $1^{\circ}$ bimestre, $1^{\circ} \mathrm{AAP}$, os resultados da unidade escolar foram inferiores à média estadual. $\mathrm{Na} 1^{\circ}$ Série o percentual de acertos foi de $44 \%$ na UE e de $54 \%$ na rede. Para a $2^{\circ}$ Série os resultados foram de $46 \%$ na escola analisada e de $51 \%$ na rede e de $49 \%$ na UE e de $54 \%$ na rede para a $3^{\circ}$ Série do Ensino Médio.

Analisando o percentual de acertos ao final do $2^{\circ}$ bimestre, $2^{\circ}$ AAP, tanto a unidade escolar como a rede estadual apresentaram os mesmos resultados, de $46 \%$ de acertos na $1^{\circ}$ Série e para a $2^{\circ}$ Série com $55 \%$ de acertos. Na $3^{\circ}$ Série o desempenho foi de $46 \%$ na unidade escolar e de $49 \%$ na rede.

Assim, como mencionada ao comparar a participação, os resultados do percentual de acertos nas avaliações de Matemática no $1^{\circ}$ semestre do ano letivo de 2021 ilustram uma potencial defasagem no processo de aprendizagem, pois os dados estão próximos a $50 \%$, indicando este como o percentual de aprendizagem do conteúdo.

Uma análise mais ampla das habilidades contempladas em cada avaliação e a comparação do percentual em cada habilidade trará um panorama mais completo da realidade do sistema de ensino híbrido na rede estadual paulista. 


\section{RECIMA21 - REVISTA CIENTÍFICA MULTIDISCIPLINAR ISSN 2675-6218}

ENSINO HÍBRIDO E DESEMPENHO EM MATEMÁTICA NO ENSINO MÉDIO NA REDE PÚBLICA DO ESTADO DE SÃO PAULO Marco Antonio Campos

\section{CONSIDERAÇÕES FINAIS}

Com o agravamento da pandemia mundial de Covid-19 a Secretaria de Educação do Estado de São Paulo, Seduc-SP, suspendeu as aulas presenciais e passou a aplicar o ensino híbrido, isto é, os estudantes frequentavam períodos de aula presencial e períodos de aulas on-line, numa espécie de revezamento entre as turmas, que foi variável para cada unidade escolar em função do número de alunos, turmas entre outros fatores.

Para o ano letivo de 2022, a Seduc-SP implantará no Ensino Médio uma espécie de ensino híbrido, independentemente da situação sanitária, pois será oferecido disciplinas no formato on-line e fora do horário padrão das aulas. Com isso tornam-se necessárias ações contínuas de aperfeiçoamento dos professores para obter o máximo de participação e desempenho dos estudantes neste tipo de ensino (OLIVEIRA et al., 2021).

Nestas condições, a verificação da participação e do desempenho, na disciplina de Matemática em avaliações padronizadas da Seduc-SP, torna-se necessária, pois trará um panorama de acesso dos estudantes a este formato de aulas e apontará se sua participação é suficiente para o aprendizado mínimo.

Entretanto, quase a totalidade dos professores da rede estadual paulista não tiveram em sua graduação disciplinas referentes ao sistema de ensino híbrido, pois tal metodologia não é contemplada na grade curricular dos cursos superiores.

Soma-se a estes fatores a pouca oferta de cursos de pós-graduação sobre este tema. Assim, os professores passaram a lecionar suas aulas em um formato pouco habitual a situação dos anos anteriores (NOVELLO; LAURINO, 2012; PERES, 2020; MENEZES, et al., 2021).

Destaca-se que a pandemia mundial de Covid-19, que forçou este tipo de ensino não estava programada. Mesmo assim a Seduc-SP ofereceu meios, como subsídio para a compra de equipamentos de informática aos professores e fornecimento de chips de celulares para alunos e professores.

Na primeira etapa, na oferta de recursos para acompanhamento das aulas on-line, a Seduc-SP ofereceu meios para que o ensino fosse aplicado com sucesso na rede, porém, os dados, conforme apresentados neste trabalho, ficaram aquém daqueles obtidos quando do ensino no formato presencial.

As próprias ferramentas de TICs (Tecnologia da Informação e Comunicação) empregadas nas aulas on-line transmitidas pela Seduc-SP, onde havia apenas um chat, para toda a rede, no qual o aluno poderia expressar sua dúvida ou questionamento através de uma frase escrita, sem a confirmação de ter sua dúvida sanada, diminui o interesse, a participação e a interação entre professor/aluno nestas aulas (CAMPOS, 2021).

Até uma questão cultural pode explicar este baixo nível de participação e desempenho, pois muitos dos alunos, encaram os recursos de informática como uma ferramenta de lazer e distração e não como um instrumento de trabalho e, principalmente de estudo na educação básica, pois esta metodologia é mais comum para os ensinos técnico e superior (CUTOLO; ALVES, 2021). 


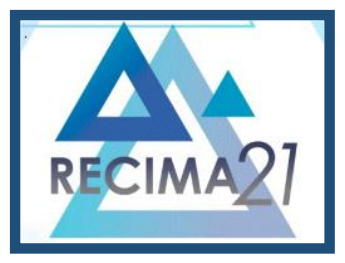

\section{RECIMA21 - REVISTA CIENTÍFICA MULTIDISCIPLINAR ISSN 2675-6218}

A metodologia das aulas on-line, que foram apenas apresentadas no formato de transmissão de aula, poderia ser adequada a realidade da rede estadual paulista, onde atribui ao baixo índice de participação à dificuldade de acesso à internet e aos recursos de informática. Destaca-se nesta metodologia de aula do ensino híbrido ações como:

- Aulas invertidas com o aluno estudando antecipadamente, no ambiente virtual, o conteúdo teórico, para quando na participação presencial esclarecer suas dúvidas, realizar exercícios e interagir com seus colegas, potencializando o desempenho;

- Rotação de laboratório: foi a metodologia aplicada de forma adaptada na rede, pois houve um rodízio entre os estudantes, assim parte realizada atividade das aulas on-line e parte na aula presencial;

- Rotação por estações: com a dificuldade de acesso à internet esta atividade não foi contemplada, pois ela deve ocorrer quando na etapa do ensino off-line, isto é, o professor, durante as aulas presenciais divide a turma em grupos e cada qual faz determinada atividade, ao final os grupos vão trocando de estações até realizarem todas as atividades;

- Rotação individual: talvez a atividade mais aplicada, não só durante o período do ensino híbrido, mas durante principalmente o processo de recuperação paralela, pois consiste na oferta de atividades individuais para cada aluno de acordo com sua dificuldade em determinado conteúdo (FURQUIM, 2019).

Quando da participação dos estudantes no seu período de aula presencial, a rotação individual, talvez tenha sido a metodologia mais aplicada em toda a rede, pois os professores buscaram recuperar a defasagem dos alunos durante as aulas on-line, por este motivo, pode-se atribuir o desempenho próximo de $50 \%$ a esta metodologia.

Analisando o percentual de participação e de acertos, na disciplina de Matemática, para as séries do Ensino Médio, de uma escola estadual pertencente a Diretoria de Ensino de Mogi Mirim e comparando seus resultados com a média da rede estadual nas avaliações padronizadas da SeducSP no $1^{\circ}$ semestre do ano letivo de 2021 , o qual a metodologia de ensino foi classificada como ensino híbrido, indica índices próximos a 50\%.

Portanto, atualizações na metodologia do ensino híbrido somadas a maior disponibilidade de acesso a este tipo de ensino e principalmente na formação e atualização profissionais dos docentes são imprescindíveis para a maior participação e consequente melhoria do desempenho dos estudantes.

\section{REFERÊNCIAS}

BRASIL. MINISTÉRIO DA EDUCAÇÃO - MEC. CONSELHO NACIONAL DE EDUCAÇÃO - CNE. Proposta de parecer sobre reorganização dos calendários escolares e realização de atividades pedagógicas não presenciais durante o período de pandemia da Covid-19. Disponível em: http://portal.mec.gov.br/docman/marco-2020-pdf/144511-texto-referencia-reorganizacao-doscalendarios-escolares-pandemia-da-covid-19/file. Acesso em: 01 nov. 2021.

CAMPOS, M. A. Níveis de Proficiência em Matemática nas Escolas Estaduais do Estado de São Paulo. Revista Mais Educação, v. 4, n. 8, p. 1030-1038, 2021. 


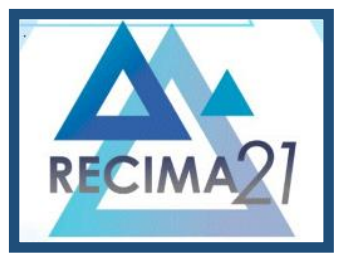

\section{RECIMA21 - REVISTA CIENTÍFICA MULTIDISCIPLINAR ISSN 2675-6218}

ENSINO HÍBRIDO E DESEMPENHO EM MATEMÁTICA NO ENSINO MÉDIO NA REDE PÚBLICA DO ESTADO DE SÃO PAULO Marco Antonio Campos

CUTOLO, A.; ALVES, D. de L. A educação remota em tempos de pandemia mundial: desafios \& avanços. Congresso Interdisciplinar de Educação - INTEREdu 2020, In: Anais..., EDUCAÇÃO E DESENVOLVIMENTO. Rio de Janeiro: Pembroke Collins, 2021. p. 123-135.

FURQUIM, D. Ensino híbrido: o que é e como pode ser usado na escola. Disponível em: https://escolasdisruptivas.com.br/metodologias-inovadoras/ensino-hibrido-o-que-e-e-como-pode-serusado-na-escola/. Acesso em: 03 nov. 2021.

MENEZES, A da S.; FERRO, D. B.; ROCHA, J. S.; SILVA, J. E. Formação do professor no ensino da Matemática em tempos de isolamento social no ensino híbrido: uma revisão sistemática. Research, Society and Development, v. 10, n. 5, e43810515162, 2021.

MORAN, J. Educação Híbrida - Um conceito-chave para a educação, hoje. In: BACICH, L.; TANZI NETO, A.; TREVISANI, F de M. Ensino híbrido: personalização e tecnologia na educação. Porto Alegre: Penso, 2015.

NOVELLO, T. P.; LAURINO, D. P. Educação a distância: seus cenários e autores. Revista Iberoamericana de Educación / Revista Ibero-americana de Educação, n.ํ58/4, 2012.

OLIVEIRA, M. B.; SILVA, L. C. T.; CANAZARO, J. V.; CARVALHIDO, M. L. L.; SOUZA, R. R. C. D.; BUSSADE NETO, J.; RANGEL, D. P.; PELEGRINO, J. F. M. O ensino híbrido no Brasil após pandemia do covid 19. Brazilian Journal of Development, v. 7, n. 1, p. 918, 2021.

PERES, M. R. Novos desafios da gestão escolar e de sala de aula em tempos de pandemia. Revista Administração Educacional, v.11, n. 1, p. 20-31, 2020.

PLATAFORMA CAED. CURSO DESENVOLVIMENTO PROFISSIONAL EM AVALIAÇÃO EDUCACIONAL: Capacitação para o uso dos resultados das atividades avaliativas na gestão do currículo.

em: https://avaliacaoemonitoramentosaopaulo.caeddigital. $\mathrm{net} / \mathrm{mdl} / \mathrm{mod} / \mathrm{page} / \mathrm{view} . \mathrm{php}$ ?id=91\&forceview=1 . Acesso em: 20 ago. 2021. (a)

PLATAFORMA CAED. Resultados das avaliações. Disponível em: https://avaliacaoemonitoramentosaopaulo.caeddigital.net/\#!/resultados-estudantes. Acesso em: 06 set. 2021. (b)

SOUTO, L. Um em cada cinco brasileiros não tem acesso à internet, segundo IBGE - Pnad Contínua indica ainda desigualdade de acesso entre estudantes. Disponível em: https://agenciabrasil.ebc.com.br/radioagencia-nacional/geral/audio/2021-04/um-em-cada-cincobrasileiros-nao-tem-acesso-internet-segundo-ibge. Acesso em: 01 nov. 2021. 